\title{
Active behaviour of terrestrial caterpillars on the water surface
}

\author{
Masakazu Hayashi ${ }^{\text {Corresp., } 1}$, Shinji Sugiura ${ }^{\text {Corresp. } 2}$ \\ ${ }^{1}$ Hoshizaki Green Foundation, Izumo, Shimane, Japan \\ ${ }^{2}$ Graduate School of Agricultural Science, Kobe University, Kobe, Hyogo, Japan \\ Corresponding Authors: Masakazu Hayashi, Shinji Sugiura \\ Email address: hgf-haya@green-f.or.jp, ssugiura@people.kobe-u.ac.jp
}

Most butterfly and moth larvae (Lepidoptera) are terrestrial. When terrestrial caterpillars accidentally fall into water, they may drown or be preyed upon by aquatic predators before they can safely reach land. However, how terrestrial caterpillars escape aquatic environments and predators remains unclear. In July 2018, we observed a terrestrial caterpillar actively moving forward on the surface of a pond in Japan until it successfully reached the shore. To further investigate this behaviour in terrestrial caterpillars, we experimentally placed larvae of 13 moth species (four families) on a water surface under laboratory and field conditions. All caterpillars floated. Larvae of seven species moved forward on the water surface, whereas those of six species did not. Two types of behaviour were observed; in Dinumma deponens, Hypopyra vespertilio, Spirama retorta, Laelia coenosa, Lymantria dispar (all Erebidae), and Naranga aenescens (Noctuidae), larvae swung their bodies rapidly from side to side to propel themselves along the water surface (i.e., undulatory behaviour); in contrast, larvae of Acosmetia biguttula (Noctuidae) rapidly moved the abdomen (posterior segments) up and down for propulsion along the water surface (i.e., flick behaviour). Although thoracic legs were not used for undulatory and flick behaviour, rapid movements of the abdomen were used to propel caterpillars on the water surface. We also observed that undulatory and flick behaviour on the water surface aided caterpillars in escaping aquatic predators under field conditions. In addition, we investigated the relationship between body size and undulatory behaviour on the water surface in the erebid $S$. retorta under laboratory conditions. The frequency and speed of forward movement on the water surface increased with body length. Together, these results show that the rapid movement of elongated bodies results in forward propulsion on the water surface, allowing some terrestrial caterpillars to avoid drowning or aquatic predators. We further suggested potential factors related to morphology, host plant habitat, and defensive behaviour that may have led to the acquisition of aquatic behaviour in terrestrial caterpillars.

Peer] reviewing PDF | (2020:07:50831:3:0:NEW 19 Jul 2021) 


\section{Active behaviour of terrestrial caterpillars on the water surface}

2

3 Masakazu Hayashi ${ }^{1}$ and Shinji Sugiura ${ }^{2}$

4

$5 \quad{ }^{1}$ Hoshizaki Green Foundation, Sono, Izumo, Shimane, 691-0076 Japan.

$6 \quad{ }^{2}$ Graduate School of Agricultural Science, Kobe University, 1-1 Rokkodai, Nada-ku, Kobe, 657-

78501 Japan.

8

9 Corresponding authors:

10 Masakazu Hayashi, hgf-haya@green-f.or.jp

11 Shinji Sugiura, ssugiura@people.kobe-u.ac.jp

12

13 Running title (40 characters): Caterpillar behaviour on water

14 
15 ABSTRACT (word limit: 500)

16 Most butterfly and moth larvae (Lepidoptera) are terrestrial. When terrestrial caterpillars

17 accidentally fall into water, they may drown or be preyed upon by aquatic predators before they

18 can safely reach land. However, how terrestrial caterpillars escape aquatic environments and

19 predators remains unclear. In July 2018, we observed a terrestrial caterpillar actively moving

20 forward on the surface of a pond in Japan until it successfully reached the shore. To further

21 investigate this behaviour in terrestrial caterpillars, we experimentally placed larvae of 13 moth

22 species (four families) on a water surface under laboratory and field conditions. All caterpillars

23 floated. Larvae of seven species moved forward on the water surface, whereas those of six

24 species did not. Two types of behaviour were observed; in Dinumma deponens, Hypopyra

25 vespertilio, Spirama retorta, Laelia coenosa, Lymantria dispar (all Erebidae), and Naranga

26 aenescens (Noctuidae), larvae swung their bodies rapidly from side to side to propel themselves

27 along the water surface (i.e., undulatory behaviour); in contrast, larvae of Acosmetia biguttula

28 (Noctuidae) rapidly moved the abdomen (posterior segments) up and down for propulsion along

29 the water surface (i.e., flick behaviour). Although thoracic legs were not used for undulatory and

30 flick behaviour, rapid movements of the abdomen were used to propel caterpillars on the water

31 surface. We also observed that undulatory and flick behaviour on the water surface aided

32 caterpillars in escaping aquatic predators under field conditions. In addition, we investigated the

33 relationship between body size and undulatory behaviour on the water surface in the erebid $S$.

34 retorta under laboratory conditions. The frequency and speed of forward movement on the water

35 surface increased with body length. Together, these results show that the rapid movement of

36 elongated bodies results in forward propulsion on the water surface, allowing some terrestrial

37 caterpillars to avoid drowning or aquatic predators. We further suggested potential factors related

38 to morphology, host plant habitat, and defensive behaviour that may have led to the acquisition 
39 of aquatic behaviour in terrestrial caterpillars.

40

41 Keywords: anguilliform, aquatic behaviour, Erebidae, Lepidoptera, Noctuidae, swim

42

43 


\section{INTRODUCTION}

45 Most terrestrial insects have not adapted to aquatic environments; for example, many terrestrial insect species only rarely escape from a water surface. However, terrestrial insects such as locusts, cockroaches, praying mantises, and ants can swim on a water surface using their legs (Miller, 1972; Franklin, Jander \& Ele, 1977; Pflüger \& Burrows, 1978; Graham et al., 1987;

Bohn, Thornham \& Federle, 2012; Yanoviak \& Frederick, 2014; Gripshover, Yanoviak \& Gora, 2018). Swimming behaviour has been reported for the adult stages of terrestrial insects, but rarely for the immature stages.

The larvae of butterflies and moths (Lepidoptera) are predominantly terrestrial; however, approximately $0.5 \%$ of 157,000 known species are aquatic at the larval stage (van Nieukerken et al. 2011; Pabis, 2018). When terrestrial caterpillars accidentally fall into water, they can drown or be preyed upon by aquatic predators such as fish before they can safely reach land (Gustafsson, Greenberg \& Bergman, 2014; Iguchi et al., 2004). Some caterpillars (i.e., aquatic species) exhibit behavioural adaptations to aquatic environments and predators to avoid these risks (Pabis, 2018), but the behavioural responses of terrestrial caterpillars to aquatic environments remain unclear.

60 On July 20, 2018, we observed a terrestrial caterpillar of Dinumma deponens Walker

61 (Lepidoptera: Erebidae) moving forward on the water surface of a pond in Unnan, Shimane,

62 Japan. The caterpillar undulated from side to side, propelling itself forward on the water surface;

63 it was able to successfully reach the shore (Fig. 1a). The caterpillar may have accidentally fallen

64 into the pond because $D$. deponens larvae feed on leaves of the tree species Albizia julibrissin

65 Durazz. (Fabaceae), which commonly grows along the edges of wetlands (Kishida, 2011). We

66 placed the same caterpillar on the water surface again and observed the same behaviour (Fig. 1b;

67 Video S1). This active behaviour on the water surface appeared to avoid drowning and aquatic 
68 predators (e.g., water striders; Fig. 1b; Video S1).

69 To investigate the water surface behaviour in terrestrial caterpillars further, we experimentally 70 placed the larvae of 13 moth species (belonging to four families), including $D$. deponens, onto a 71 water surface and observed their behaviour under laboratory and field conditions. In addition, we 72 experimentally investigated the relationship between caterpillar body size and aquatic behaviour 73 to clarify how body size can influence propulsive power in water.

75 MATERIALS AND METHODS

76 To test whether terrestrial caterpillars can move forward on the water surface, we experimentally 77 placed the larvae of 13 moth species (from four families) on a water surface and observed their 78 behaviour under laboratory and field conditions (Table 1). We collected 52 larvae from eight 79 plant species from June 2019 to July 2019 in Shimane Prefecture and in June 2020 in Hyogo 80 Prefecture, Japan. We carefully placed each caterpillar $(n=49)$ on the water surface in a plastic 81 vessel $(390 \times 265 \times 65 \mathrm{~mm})$ containing $2 \mathrm{~L}$ of water $\left(20 \mathrm{~mm}\right.$ depth, $\left.25^{\circ} \mathrm{C}\right)$ under well-lit 82 conditions, with an air temperature of $25^{\circ} \mathrm{C}$. We also placed the larvae of three species, 83 Hypopyra vespertilio (Fabricius) (Erebidae), Acosmetia biguttula (Motschulsky) (Noctuidae), 84 and Theretra oldenlandiae (Fabricius) (Sphingidae), on the surfaces of ponds in Shimane 85 Prefecture. During each 2-min observation period, we investigated whether the larvae (1) 86 remained at the water surface (supported by water tension) and (2) moved forward on the water

87 surface. To examine the possible origins of aquatic behaviour, we also observed how caterpillars 88 of each species walk on twigs or leaves (i.e., inching or crawling; van Griethuijsen \& Trimmer, 89 2014; Table 1). We identified each caterpillar based on their morphological characteristics (Sugi, 90 1987; Yasuda, 2010, 2012, 2014; Suzuki et al., 2018), and raised some larvae to the adult stage 91 to confirm their identity (Kishida, 2011). 
92 In caterpillars, various types of behaviour such as anti-predator defences are closely related to

93 body size (Sugiura \& Yamazaki, 2014; Hossie et al., 2015; Sugiura, 2020; Sugiura et al., 2020).

94 To clarify how caterpillar size can influence propulsive power in water, we experimentally

95 investigated the relationship between body size and water surface behaviour in the erebid

96 Spirama retorta (Clerck) (Erebidae). We reared S. retorta larvae from the eggs of two females

97 on Albizia julibrissin leaves under laboratory conditions $\left(26-29^{\circ} \mathrm{C}\right)$. Spirama retorta passes

98 through seven larval instars before pupation (Table 2). We measured the body weight of each

99 larva to the nearest $1 \mathrm{mg}$ using an electronic balance (CJ-620S; Shinko Denshi, Co., Ltd., Tokyo,

100 Japan); we measured the body length and head capsule width to the nearest $0.01 \mathrm{~mm}$ using slide

101 callipers or an ocular micrometre. We placed 10 larvae per instar individually on the water

102 surface in a plastic vessel $(390 \times 265 \times 65 \mathrm{~mm})$ with $2 \mathrm{~L}$ of water $(20 \mathrm{~mm}$ depth $)$ under well-lit

103 conditions at $25^{\circ} \mathrm{C}$. We filmed the behaviour of the larvae $(n=70)$ using video cameras (V2;

104 Nikon, Tokyo, Japan). We played back the footage of the recorded behaviour using iMovie

105 version 10.0.6 (Apple, Inc., Cupertino, CA, USA). During each 2-min observation period, we

106 recorded (1) whether the larva remained at the water surface (supported by water tension), (2)

107 whether the larva moved forward on the water surface, and (3) the distance ( $\mathrm{mm}$ ) travelled by the 108 larva in $2 \mathrm{~s}$.

109 To investigate the relationship between larval body length and aquatic behaviour in S. retorta,

110 we ran a generalised linear model with a binomial error distribution and logit link function (i.e.,

111 logistic regression). We used 10 individuals per instar $(n=70)$ for the analysis. We used forward

112 movement (1) or non-forward movement (0) on a water surface as the binary response variable;

113 we regarded body length as a fixed factor. We also ran a generalised linear model with a Poisson

114 error distribution and log link function (i.e., Poisson regression) to investigate the relationship

115 between body size and movement distance in $S$. retorta, analysing 10 individuals per instar $(n=$ 
116 70). We used forward speed $(\mathrm{mm} / \mathrm{s})$ as the response variable; we regarded body length as a fixed

117 factor. When the residual deviance was smaller (underdispersion) or larger (overdispersion) than

118 the residual degrees of freedom, we used a quasi-binomial or quasi-Poisson error distribution,

119 respectively, rather than a binomial or Poisson error distribution (Sugiura \& Sato, 2018). We

120 performed all analyses using $\mathrm{R}$ software version 3.5.2 (R Core Team, 2019).

121

\section{RESULTS}

123 All caterpillars examined in this study floated (i.e., remained at the water surface). Larvae from

124 six of the 13 caterpillar species did not move forward on the water surface, whereas larvae from

125 seven species (two families: Erebidae and Noctuidae) moved forward on the water surface

126 (Table 1). Two types of behaviour were observed (Table 1): larvae of Dinumma deponens,

127 Hypopyra vespertilio, Spirama retorta, Laelia coenosa (Hübner), Lymantria dispar (Linnaeus)

128 (all Erebidae), and Naranga aenescens Moore (Noctuidae) swung their bodies side to side

129 quickly to propel themselves on the water surface (i.e., undulatory behaviour; Figs. 1c-e, 2a;

130 Video S2), while larvae of Acosmetia biguttula (Noctuidae) moved the posterior segments of the

131 abdomen up and down quickly to propel themselves on the water surface (i.e., flick behaviour;

132 Figs. 1f, 2b; Video S3). Thoracic legs were not used for undulatory or flick behaviour(Videos S2,

133 S3). One larva of Acosmetia biguttula was observed escaping from an aquatic predator

134 (Notonecta triguttata Motschulsky) in a pond (Video S3).

135 The relationship between body size and undulatory behaviour in S. retorta was investigated

136 under laboratory conditions. All larvae floated (Table 2). The frequency of forward movement

137 on the water surface increased with body length (Fig. 3a; Tables 2 and 3): $0 \%, 0 \%, 40 \%, 70 \%$,

$138100 \%, 100 \%$, and $100 \%$ of the first, second, third, fourth, fifth, sixth, and seventh instars moved

139 forward on the water surface, respectively (Table 2). Furthermore, the forward speed (mm/s) 
140 increased with body length (Fig. 3b; Table 4).

141 Larvae from eight of the 13 caterpillar species moved in a characteristic looping manner on

142 leaves or stems (i.e., inching; Table 1), whereas larvae from five species moved their abdomen

143 up and down on land (i.e., crawling; Table 1). When disturbed, larvae of $H$. vespertilio, S. retorta,

144 and $D$. deponens were frequently observed to bend their bodies violently from side to side.

145

146 DISCUSSION

147 Active behaviour on/under the water surface has been reported in some aquatic and semi-aquatic

148 caterpillars (Welch, 1914; Mey \& Speidel, 2008; Meneses et al., 2013; Coates \& Abel, 2019; De-

149 Freitas, De Agostini \& Stefani, 2019). The aquatic larvae of Paracles klagesi (Rothschild)

150 (Erebidae: Arctiinae) and Neoschoenobia testacealis Hampson (Crambidae) move and feed

151 under the water surface (Nagasaki, 1992; Meneses et al., 2013), and semi-aquatic larvae of

152 moths such as Bellura vulnifica (Grote) (Noctuidae) and Ostrinia penitalis (Grote) (Crambidae)

153 can move forward on the water surface (Welch, 1914; Coates \& Abel, 2019). However, few

154 studies have examined whether typically terrestrial caterpillars can swim on or under the water

155 surface. In the present study, we observed the behaviour on water surfaces of 13 terrestrial

156 caterpillar species from four families under laboratory and field conditions. Among these, seven

157 species were observed to move forward on the water surface (Figs. 1 and 2; Table 1), although

158 none broke through the surface tension. We also observed two types of behaviour on the water

159 surface (undulatory and flick behaviour) in the caterpillars (Figs. 1 and 2; Table 1). The

160 undulatory behaviour observed in this study was similar to anguilliform movement, which has

161 been reported in slender-bodied animals such as eels, snakes, and centipedes (Graham et al.,

162 1987; Sfakiotakis, Lane \& Davies, 1999; Yasui et al., 2019). The frequency and speed of

163 undulatory behaviour increased with body length in Spirama retorta larvae (Fig. 3; Tables 3 and 
164 4). Directed movements on the water surface can help caterpillars to avoid aquatic predators 165 (Video S1).

166 All of the terrestrial caterpillars used in the present study floated due to water surface tension.

167 Some, but not all, of these floating caterpillars moved forward on the water surface (Table 1).

168 Three factors may influence forward movement on the water surface in terrestrial caterpillars: (1)

169 morphology, (2) host plant habitat, and (3) locomotive and defensive behaviour.

170 Caterpillars that exhibited forward movement on the water surface had distinct morphological

171 traits such as relatively elongated bodies. In this study, long-bodied caterpillars were more

172 capable of forward movement on the water surface than those with short bodies (Fig. 3a; Table

173 3). This relationship has been suggested to explain the behaviour of the semi-aquatic caterpillar

174 species Bellura vulnifica, although its morphological traits were not quantified (Welch, 1914). In

175 addition, long body setae may assist in floating on the water surface in hairy caterpillars, such as

176 those of Laelia coenosa and Lymantria dispar (Meyer-Rochow, 2016). However, these features

177 certainly evolved for reasons other than aquatic behaviour, because long bodies, prolegs, and

178 body hairs have other important functions in their terrestrial habitats, e.g., they may be involved

179 in natural enemy defence, maintaining their perch, and still others (Fig. 4; Skelhorn et al., 2010;

180 van Griethuijsen \& Trimmer, 2014; Sugiura \& Yamazaki, 2014).

181 Caterpillars use silk threads extruded from their spinnerets to disperse aerially (Bell et al.,

182 2005) or drop from the host plant to escape natural enemies (Sugiura \& Yamazaki, 2006).

183 However, many mature microlepidopteran caterpillars descend from the host plant to the ground

184 for pupation (Sugi, 1987). Caterpillars inhabiting host plants growing along watercourses may

185 accidentally descend into open water. Six of the seven caterpillar species observed moving

186 forward on the water surface in this study were collected from waterside plants such as Albizia

187 julibrissin (Table 1). 
188 Terrestrial behaviour can provide insight into the origins of aquatic behaviour in terrestrial

189 caterpillars. Some caterpillars that undulated on the water surface typically locomote in a

190 characteristic looping manner on leaves or stems (i.e., inching; van Griethuijsen \& Trimmer,

191 2014; Table 1). When disturbed, some larvae of Hypopyra vespertilio, S. retorta, and Dinumma

192 deponens violently bent their bodies from side to side (i.e., jerking, twisting, or thrashing

193 behaviour; Gross 1993; Greeney, Dyer \& Smilanich, 2012). Undulating behaviour on the water

194 surface may have originated from this defensive behaviour, rather than walking behaviour. Some

195 caterpillars that exhibited flick behaviour typically moved their abdomen up and down to move

196 on land (i.e., crawling; van Griethuijsen \& Trimmer, 2014; Table 1); the similarity of the flick

197 behaviour and crawling motions suggests that flick behaviour on the water surface may have

198 originated from crawling motion.

199

200 CONCLUSIONS

201 Our results showed that some terrestrial caterpillars exhibited forward movement on the water

202 surface to avoid drowning and aquatic predators (Table 1; Videos S1, S3). This behaviour is

203 similar to the swimming behaviour reported in many aquatic and terrestrial animals (Graham et

204 al., 1987; Sfakiotakis, Lane \& Davies, 1999; Yasui et al., 2019). The behaviour found in this

205 study was observed in only two of the four lepidopteran families tested: Erebidae and Noctuidae

206 (Table 1). Our investigation was limited to four families, although the insect order Lepidoptera

207 contains 133 recognised families (Mitter, Davis \& Cummings, 2017). Thus, the behaviour

208 observed in the erebids and noctuids sampled in this study will probably be found in other

209 lepidopteran families. Differences in aquatic skill among species should be investigated.

210 Kinematic and anatomical studies would help elucidate the different mechanisms of aquatic

211 behaviour in these and still other lepidopteran caterpillars. 


\section{ACKNOWLEDGEMENTS}

214 We thank the editor and reviewers for their helpful comments on an earlier version of the

215 manuscript. We also thank K. Sakagami for aiding in moth identification and K. Okai for

216 assistance with caterpillar sampling.

217

\section{Author Contributions}

219 Masakazu Hayashi conceived and designed the experiments, performed the experiments, contributed reagents/materials/analysis tools, prepared figures and/or tables, authored or reviewed drafts of the paper, and approved the final draft.

Shinji Sugiura conceived and designed the experiments, performed the experiments, analysed

223 the data, contributed reagents/materials/analysis tools, prepared figures and/or tables, authored or 224 reviewed drafts of the paper, and approved the final draft.

226 Animal Ethics

227 The following information was supplied relating to ethical approvals (i.e., approving body and 228 any reference numbers):

229 The experiments were undertaken in accordance with the Kobe University Animal 230 Experimentation Regulations (Kobe University's Animal Care and Use Committee, 30-01).

231 Ours study was not conducted in any national parks or protected areas. Study insects were not 232 protected species; no specific permissions are required to collect non-protected insects in non233 protected areas in Japan.

\section{Supplemental Information}


236 Supplemental information for this article can be found online at http://dx.doi.org/

237

238

239

240

241

242

243

244

245

246

247

248

249

250

251

252

253

\section{REFERENCES}

Bell JR, Bohan DA, Shaw EM, Weyman GS. 2005. Ballooning dispersal using silk: world fauna, phylogenies, genetics and models. Bulletin of Entomological Research 95: 69-114. DOI 10.1079/BER2004350.

Bohn HF, Thornham DG, Federle W. 2012. Ants swimming in pitcher plants: kinematics of aquatic and terrestrial locomotion in Camponotus schmitzi. Journal of Comparative Physiology A 198: 465-76 DOI 10.1007/s00359-012-0723-4.

Coates BS, Abel CA. 2019. Differentiation of European corn borer (Lepidoptera: Crambidae) and American lotus borer (Lepidoptera: Crambidae), Ostrinia penitalis, from north American field collections. Journal of Economic Entomology 112: 2007-2011 DOI 10.1093/jee/toz078.

De-Freitas I, De Agostini J, Stefani V. 2019. The aquatic Lepidopterans: a mysterious and unknown fauna. In: Del-Claro K, Guillermo R, eds. Aquatic insects. Cham: Springer, 341347. DOI 10.1007/978-3-030-16327-3_13.

Franklin R, Jander R, Ele K. 1977. The coordination, mechanics and evolution of swimming by a grasshopper, Melanoplus differentialis (Orthoptera: Acrididae). Journal of the Kansas Entomological Society 50: 189-199.

Graham JB, Lowell WR, Rubinoff I, Motta J. 1987. Surface and subsurface swimming of the sea snake Pelamis platurus. Journal of Experimental Biology 127: 27-44.

Greeney HF, Dyer LA, Smilanich AM. 2012. Feeding by lepidopteran larvae is dangerous: A review of caterpillars' chemical, physiological, morphological, and behavioral defenses against natural enemies. Invertebrate Survival Journal 9: 7-34. 
260 van Griethuijsen LI, Trimmer BA. 2014. Locomotion in caterpillars. Biological Reviews 89:

261

262

263

264

265

266

267

268

269

270

271

272

273

274

275

276

277

278

279

280

281

282

283 656-670 DOI 10.1111/brv.12073.

Gripshover ND, Yanoviak SP, Gora EM. 2018. A functional comparison of swimming behavior in two temperate forest ants (Camponotus pennsylvanicus and Formica subsericea) (Hymenoptera: Formicidae). Annals of the Entomological Society of America 111: 319-325 DOI 10.1093/aesa/say026.

Gross P. 1993. Insect behavioural and morphological defenses against parasitoids. Annual Review of Entomology 38: 251-273.

Gustafsson P, Greenberg LA, Bergman E. 2014. Woody debris and terrestrial invertebrates effects on prey resources for brown trout (Salmo trutta) in a boreal stream. Environmental Biology of Fishes 97: 529-542 DOI 10.1007/s10641-014-0250-y.

Hossie TJ, Skelhorn J, Breinholt JW, Kawahara AY, Sherratt TN. 2015. Body size affects the evolution of eyespots. Proceedings of the National Academy of Sciences USA 112: 6664-6669 DOI 10.1073/pnas.1415121112.

Iguchi K, Matsubara N, Yodo T, Maekawa K. 2004. Individual food niche specialization in stream-dwelling charr. Ichthyological Research 51: 321-326 DOI 10.1007/s10228-0040237-3.

Kishida Y. 2011. The standard of moths in Japan 2. Tokyo: Gakken Education Publishing (in Japanese).

Meneses AR, Bevilaqua MVC, Hamada N, Querino RB. 2013. The aquatic habit and host plants of Paracles klagesi (Rothschild) (Lepidoptera, Erebidae, Arctiinae) in Brazil. Revista Brasileira de Entomologia 57:350-352. DOI 10.1590/S0085-56262013005000025.

Mey W, Speidel W. 2008. Global diversity of butterflies (Lepidoptera) in freshwater . Hydrobiologia 595: 521-528. DOI 10.1007/s10750-007-9038-9. 
284 Meyer-Rochow B. 2016. Depilation increases while hairiness decreases the risk of drowning: A 285 hitherto unappreciated survival role of setae in woolly bear caterpillars of the moth Lemyra imparilis (Lepidoptera: Noctuoidea: Erebidae). European Journal of Entomology 113: 130_ 134 DOI 10.14411/eje.2016.016.

Miller PL. 1972. Swimming in mantids. Journal of Entomology A 46: 91-97 DOI 10.1111/j.1365-3032.1972.tb00113.x.

Mitter C, Davis DR, Cummings MP. 2017. Phylogeny and evolution of Lepidoptera. Annual Review of Entomology 62: 265-283. DOI 10.1146/annurev-ento-031616-035125.

Nagasaki O. 1992. Life history traits and resource partitioning between two coexisting aquatic pyralid moths, Elophila interruptalis (Pryer) and Neoshoenobia decoloralis Hampson (Lepidoptera). Japanese Journal of Ecology 42: 263-274 (in Japanese with English

van Nieukerken EJ, Kaila L, Kitching IJ, Kristensen NP, Lees DC, et al. 2011. Order Lepidoptera Linnaeus, 1758. Zootaxa 3148: 212-221. DOI 10.11646/zootaxa.3148.1.41.

Pabis K. 2018. What is a moth doing under water? Ecology of aquatic and semi-aquatic Lepidoptera. Knowledge \& Management of Aquatic Ecosystems 419: 42 DOI $10.1051 / \mathrm{kmae} / 2018030$.

Pflüger HJ, Burrows M. 1978. Locusts use the same basic motor pattern in swimming as in

R Core Team. 2019. R, a language and environment for statistical computing. Vienna: R Foundation for Statistical Computing.

Sfakiotakis M, Lane DM, Davies JBC. 1999. Review of fish swimming modes for aquatic locomotion. IEEE Journal of Oceanic Engineering 24: 237-252 DOI 10.1109/48.757275. 

crypsis. Science 327: 51 DOI 10.1126/science.1181931.

309 Sugi, T. 1987. Larvae of larger moths in Japan. Tokyo: Kodansha (in Japanese).

310 Sugiura S. 2020. Predators as drivers of insect defenses. Entomological Science 23: 316-337 DOI 10.1111/ens.12423.

312 Sugiura S, Sato T. 2018. Successful escape of bombardier beetles from predator digestive systems. Biology Letters 14: 20170647 DOI 10.1098/rsb1.2017.0647.

314 Sugiura S, Takanashi T, Kojima W, Kajiura Z. 2020. Squeaking caterpillars: independent 315 evolution of sonic defense in wild silkmoths. Ecology 10: e03112 DOI 10.1002/ecy.3112.

316 Sugiura S, Yamazaki K. 2006. The role of silk threads as lifelines for caterpillars: pattern and 317 significance of lifeline-climbing behaviour. Ecological Entomology 31: 52-57 DOI $318 \quad$ 10.1111/j.0307-6946.2006.00755.x.

319 Sugiura S, Yamazaki K. 2014. Caterpillar hair as a physical barrier against invertebrate 320 predators. Behavioral Ecology 24: 975-983 DOI 10.1093/beheco/aru080.

321 Suzuki T, Yokota M, Tsutsui M, Sugimoto M, Hirowatari T, Yago K. 2018. Caterpillars:

322 butterfly and moth larvae. Tokyo: Shogakukan (in Japanese).

323 Welch PS. 1914. Habits of the larva of Bellura melanopyga Grote (Lepidoptera). Biological 324 Bulletin 27: 97-114 DOI 10.2307/1535952.

325 Yanoviak SP, Frederick DN. 2014. Water surface locomotion in tropical canopy ants. Journal of Experimental Biology 217: 2163-2170 DOI 10.1242/jeb.101600.

Yasuda M. 2010. The Handbook of Japanese caterpillar. Tokyo: Bun-ichi Sogo Shuppan (in 328 Japanese).

Yasuda M. 2012. The Handbook of Japanese caterpillar II. Tokyo: Bun-ichi Sogo Shuppan (in 330 Japanese).

331 Yasuda M. 2014. The Handbook of Japanese caterpillar III. Tokyo: Bun-ichi Sogo Shuppan (in 
332 Japanese).

333 Yasui K, Kano T, Standen EM, Aonuma H, Ijspeert AJ, Ishiguro A. 2019. Decoding the

334 essential interplay between central and peripheral control in adaptive locomotion of

335 amphibious centipedes. Scientific Reports 9: 18288 DOI 10.1038/s41598-019-53258-3.

336 
337 Figure legends

338

339 Figure 1 Behaviour of terrestrial caterpillars on the water surface. (a) Dinumma deponens

340 (Erebidae). (b) Dinumma deponens moving forward on a pond surface. (c) Undulatory behaviour

341 in Spirama retorta (Erebidae). (d) Undulatory behaviour in Hypopyra vespertilio (Erebidae). (e)

342 Undulatory behaviour in Laelia coenosa (Erebidae). (f) Flick behaviour in Acosmetia biguttula

343 (Noctuidae). Arrows indicate anal prolegs. Photo credits: (a-d, f) M. Hayashi, (e) S. Sugiura.

345 Figure 2 Two types of caterpillar behaviour on the water surface. (a) Temporal sequence of

346 undulatory behaviour in Hypopyra vespertilio. (b) Temporal sequence of flick behaviour in

347 Acosmetia biguttula. Arrows indicate anal prolegs. Photo credits: (a) S. Sugiura, (b) M. Hayashi.

348

349 Figure 3 Relationship between body size and behaviour in Spirama retorta. (a) Relationship

350 between body length and frequency of undulatory behaviour $(n=70)$. (b) Relationship between

351 body length and forward speed $(\mathrm{mm} / \mathrm{s})(n=70)$. Lines and blue areas represent logistic

352 regression lines and 95\% confidence intervals derived from generalised linear models,

353 respectively (Tables 3 and 4). Photo credit: M. Hayashi.

354

355 Figure 4 Larval morphology of Hypopyra vespertilio. (a) A larva on a host plant leaf. (b) A

356 larva on the water surface. Hypopyra vespertilio larvae have three pairs of thoracic legs (T1-T3)

357 and five pairs of abdominal prolegs (A3-A6 and A10). Photo credit: S. Sugiura. 
358 Supplementary videos

359

360 Video S1. Undulatory behaviour by a Dinumma deponens larva on a pond water surface.

361 Active movement aided the larva in evading water striders [Aquarius paludum (Fabricius)].

362 Video credit: M. Hayashi.

363

364 Video S2. Undulatory behaviour by Hypopyra vespertilio larvae on water surfaces under

365 laboratory and field conditions. Video credit: S. Sugiura and M. Hayashi.

366

367 Video S3. Flick behaviour by Acosmetia biguttula larvae on water surfaces under

368 laboratory and field conditions. Active movement aided the larva in evading predation by a

369 backswimmer (Notonecta triguttata) in the pond. Video credit: M. Hayashi.

370 


\section{Table $\mathbf{1}$ (on next page)}

Table 1 Behaviour of the caterpillars placed on water surfaces. 
Table 1 Behaviour of the caterpillars placed on water surfaces.

\begin{tabular}{|c|c|c|c|c|c|c|c|c|c|}
\hline Family & Species & Instar $^{\mathrm{a}}$ & $\begin{array}{l}\text { Length } \\
(\mathrm{mm})\end{array}$ & Host plant range & $\begin{array}{l}\text { Plant species } \\
\text { (sampling) }\end{array}$ & $\begin{array}{l}\text { Habitat } \\
\text { (sampling) }\end{array}$ & $\begin{array}{l}\text { Walking } \\
\text { locomotion }\end{array}$ & $\begin{array}{l}\text { Behaviour } \\
\text { on water }{ }^{\mathrm{b}}\end{array}$ & $\begin{array}{c}\text { Forward movement } \\
\text { on water } \%(n)\end{array}$ \\
\hline \multirow[t]{5}{*}{ Erebidae } & Hypopyra vespertilio & $\mathrm{M}-\mathrm{L}$ & $23-70$ & Fabaceae & Albizia julibrissin & Lake bank & Inching & Undulatory & $100(7 / 7)^{\mathrm{c}}$ \\
\hline & Spirama retorta & $\mathrm{M}-\mathrm{L}$ & $8-42$ & Fabaceae & Albizia julibrissin & Lake bank & Inching & Undulatory & $100(3 / 3)$ \\
\hline & Dinumma deponens & $\mathrm{M}-\mathrm{L}$ & $20-32$ & Albizia julibrissin & Albizia julibrissin & Lake bank & Inching & Undulatory & $33(1 / 3)$ \\
\hline & Laelia coenosa & $\mathrm{L}$ & $22-34$ & Poaceae, Cyperaceae, Typhaceae & Typha latifolia & Pondside & Crawling & Undulatory & $100(6 / 6)$ \\
\hline & Lymantria dispar & $\mathrm{L}$ & $33-54$ & Many families & Cerasus $\times$ yedoensis & Urban area & Crawling & Undulatory & $30(3 / 10)$ \\
\hline \multirow[t]{6}{*}{ Noctuidae } & Xanthodes transversa & $\mathrm{M}-\mathrm{L}$ & $25-42$ & Malvaceae & Hibiscus mutabilis & Garden & Inching & - & $0(0 / 2)$ \\
\hline & Acosmetia biguttula & $\mathrm{M}-\mathrm{L}$ & $20-38$ & Bidens & Bidens frondosa & Pondside & Crawling & Flick & $100(6 / 6)^{\mathrm{c}}$ \\
\hline & Naranga aenescens & & & & & & & Undulatory & $100(4 / 4)$ \\
\hline & & $\mathrm{M}-\mathrm{L}$ & $13-24$ & Poaceae & Pseudoraphis sordida & Paddy field & Inching & & \\
\hline & Sarcopolia illoba & E-M & $19-34$ & Many families & Albizia julibrissin & Lake bank & Crawling & - & $0(0 / 3)$ \\
\hline & Britha inambitiosa & $\mathrm{M}-\mathrm{L}$ & $13-20$ & Pterostyrax hispidus & Pterostyrax hispidus & Streamside & Inching & - & $0(0 / 3)$ \\
\hline \multirow[t]{2}{*}{ Geometridae } & Chiasmia defixaria & $\mathrm{M}-\mathrm{L}$ & $20-30$ & Albizia julibrissin & Albizia julibrissin & Lake bank & Inching & - & $0(0 / 3)$ \\
\hline & Ectropis excellens & $\mathrm{L}$ & 30 & Many families & Pterostyrax hispidus & Streamside & Inching & - & $0(0 / 1)$ \\
\hline Sphingidae & Theretra oldenlandiae & $\mathrm{E}$ & 20 & Many families & Causonis japonica & Garden & Crawling & - & $0(0 / 1)^{\mathrm{c}}$ \\
\hline
\end{tabular}

2

3 aInstar: E, early instar; M, middle instar; L, late instar.

4 bCaterpillar behaviour on the water surface: Undulatory, forward movement by undulating; Flick, forward movement by flicking; -, non-forward movement (floating).

5 'One larva of each species was observed on the water surface of a pond, while other larvae were observed under laboratory conditions. 


\section{Table 2 (on next page)}

Table 2 Body size and forward movement on the water surface in Spirama retorta larvae. 
1 Table 2 Body size and forward movement on the water surface in Spirama retorta larvae.

\begin{tabular}{|c|c|c|c|c|c|c|}
\hline$\square$ & $\square$ & $\square$ & $\square$ & $\square$ & $\square$ & $\square$ \\
\hline Instar & Body weight $(\mathrm{mg})^{\mathrm{a}}$ & Body length $(\mathrm{mm})^{\mathrm{a}}$ & Head width $(\mathrm{mm})^{\mathrm{a}}$ & Floating $(\%)$ & Forward movement (\%) & $n$ \\
\hline First & $0.4 \pm 0.2$ & $6.1 \pm 0.2$ & $0.4 \pm 0.0$ & 100 & 0 & 10 \\
\hline Second & $8.4 \pm 1.1$ & $14.3 \pm 0.5$ & $0.7 \pm 0.0$ & 100 & 0 & 10 \\
\hline Third & $27.9 \pm 2.0$ & $22.3 \pm 0.6$ & $1.3 \pm 0.0$ & 100 & 40 & 10 \\
\hline Fourth & $79.1 \pm 5.7$ & $29.2 \pm 0.5$ & $2.0 \pm 0.0$ & 100 & 70 & 10 \\
\hline Fifth & $281.6 \pm 21.0$ & $44.4 \pm 0.9$ & $2.7 \pm 0.0$ & 100 & 100 & 10 \\
\hline Sixth & $587.4 \pm 47.6$ & $54.8 \pm 1.4$ & $3.5 \pm 0.1$ & 100 & 100 & 10 \\
\hline Seventh & $884.8 \pm 72.3$ & $61.1 \pm 1.3$ & $4.1 \pm 0.0$ & 100 & 100 & 10 \\
\hline
\end{tabular}

2

$3 \quad$ a Values are mean $\pm \mathrm{SE}$. 


\section{Table 3(on next page)}

Table 3 Relationship between body size and forward movement on the water surface in Spirama retorta larvae obtained using a generalised linear model. 
1 Table 3 Relationship between body size and forward movement on the water surface in Spirama retorta larvae obtained 2 using a generalised linear model.

\begin{tabular}{|c|c|c|c|c|c|}
\hline$\square$ & $\square$ & $\square$ & & ] & ] \\
\hline Response variable & Explanatory variable (fixed effect) & Coefficient estimate & $\mathrm{SE}$ & $t$ value & $P$ value \\
\hline Forward movement on water & Intercept & -7.21997 & 1.33807 & -5.396 & $<0.0001$ \\
\hline$\square$ & Caterpillar body length & 0.28593 & 0.05312 & 5.383 & $<0.0001$ \\
\hline
\end{tabular}

3

$4 \quad{ }^{a} A$ quasi-binomial error distribution (rather than a binomial error distribution) was used because the residual deviance was smaller 5 than the residual degrees of freedom (underdispersion).

6 


\section{Table 4 (on next page)}

Table 4 Relationship between body size and forward distance $(\mathrm{mm} / \mathrm{s})$ on the water surface in Spirama retorta larvae obtained using a generalised linear model. 
1 Table 4 Relationship between body size and forward distance $(\mathrm{mm} / \mathrm{s})$ on the water surface in Spirama retorta larvae obtained 2 using a generalised linear model.

\begin{tabular}{llcccc} 
& $\square$ & $\square$ & $\square$ & $\square$ \\
\hline Response variable & Explanatory variable (fixed effect) & Coefficient estimate & SE & $t$ value & $P$ value \\
\hline Forward distance on water ${ }^{\mathrm{a}}$ & Intercept & 0.995874 & 0.233774 & 4.26 & $<0.0001$ \\
$\square$ & Caterpillar body length & 0.056937 & 0.004376 & 13.01 & $<0.0001$ \\
\hline
\end{tabular}

3

$4 \quad{ }^{a} A$ quasi-Poisson error distribution (rather than a Poisson error distribution) was used because the residual deviance was larger than 5 the residual degrees of freedom (overdispersion).

6 


\section{Figure 1}

Figure 1 Behaviour of terrestrial caterpillars on the water surface.

(a) Dinumma deponens (Erebidae). (b) Dinumma deponens moving forward on a pond surface. (c) Undulatory behaviour in Spirama retorta (Erebidae). (d) Undulatory behaviour in Hypopyra vespertilio (Erebidae). (e) Undulatory behaviour in Laelia coenosa (Erebidae). (f) Flick behaviour in Acosmetia biguttula (Noctuidae). Arrows indicate anal prolegs. Photo credits: (a-d, f) M. Hayashi, (e) S. Sugiura. 


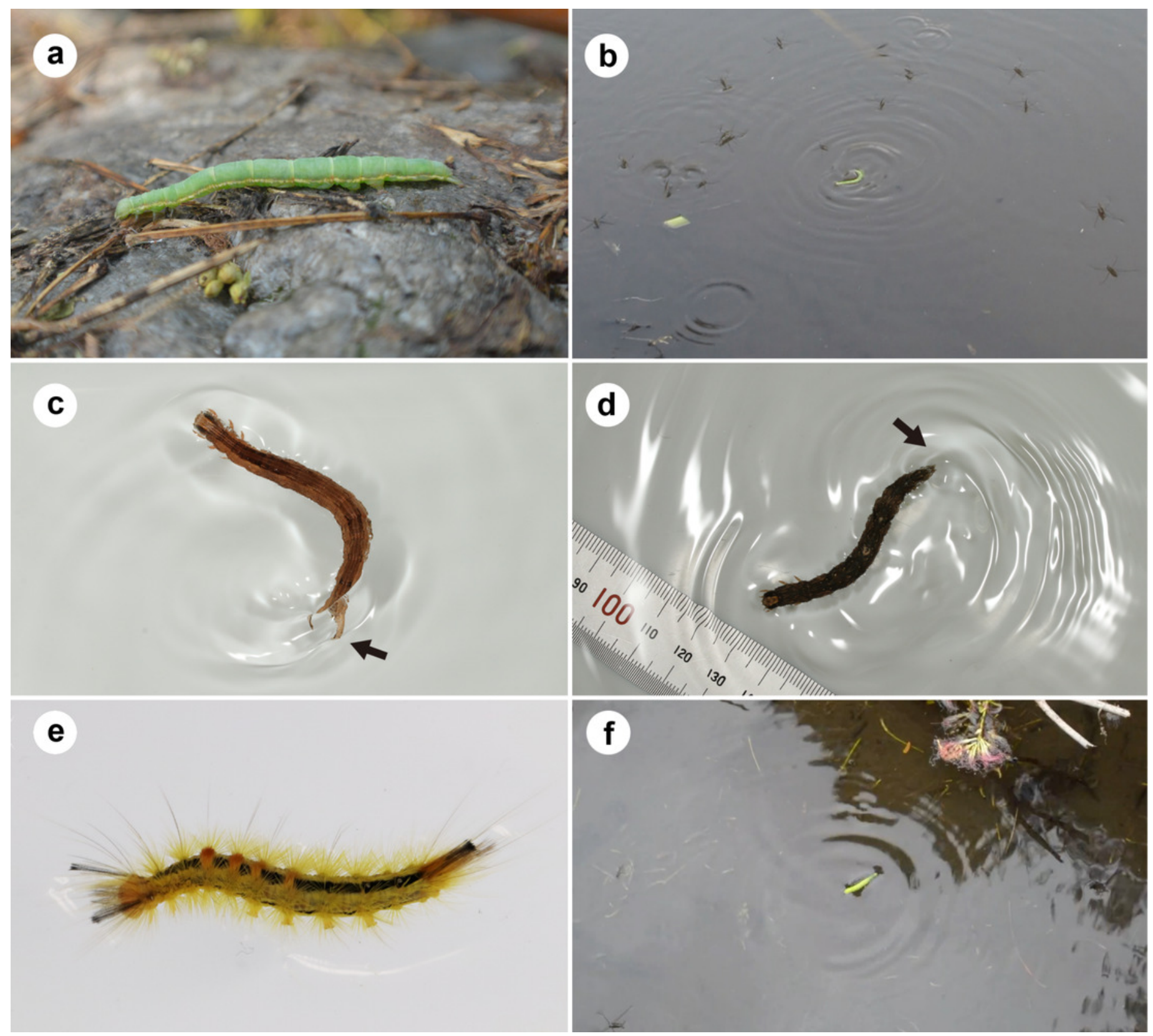


Figure 2

Figure 2 Two types of caterpillar behaviour on the water surface.

(a) Temporal sequence of undulatory behaviour in Hypopyra vespertilio. (b) Temporal sequence of flick behaviour in Acosmetia biguttula. Arrows indicate anal prolegs. Photo credits: (a) S. Sugiura, (b) M. Hayashi.

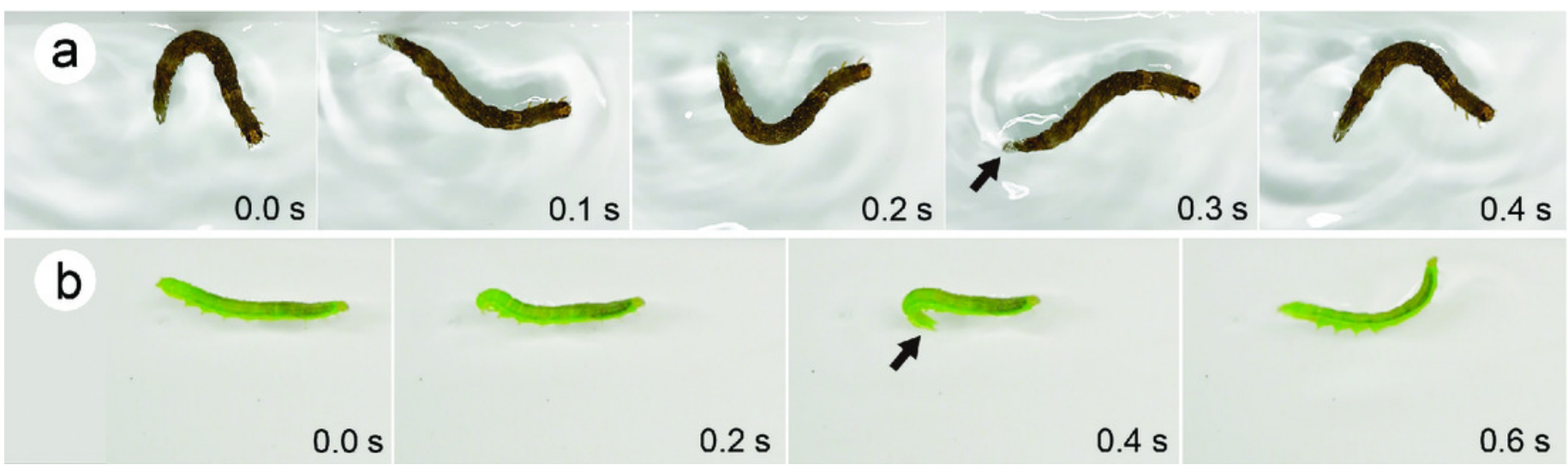


Figure 3

Figure 3 Relationship between body size and behaviour in Spirama retorta.

(a) Relationship between body length and frequency of undulatory behaviour $(n=70)$. (b) Relationship between body length and forward speed $(\mathrm{mm} / \mathrm{s})(n=70)$. Lines and blue areas represent logistic regression lines and 95\% confidence intervals derived from generalised linear models, respectively (Tables 3 and 4). Photo credit: M. Hayashi.

(a)

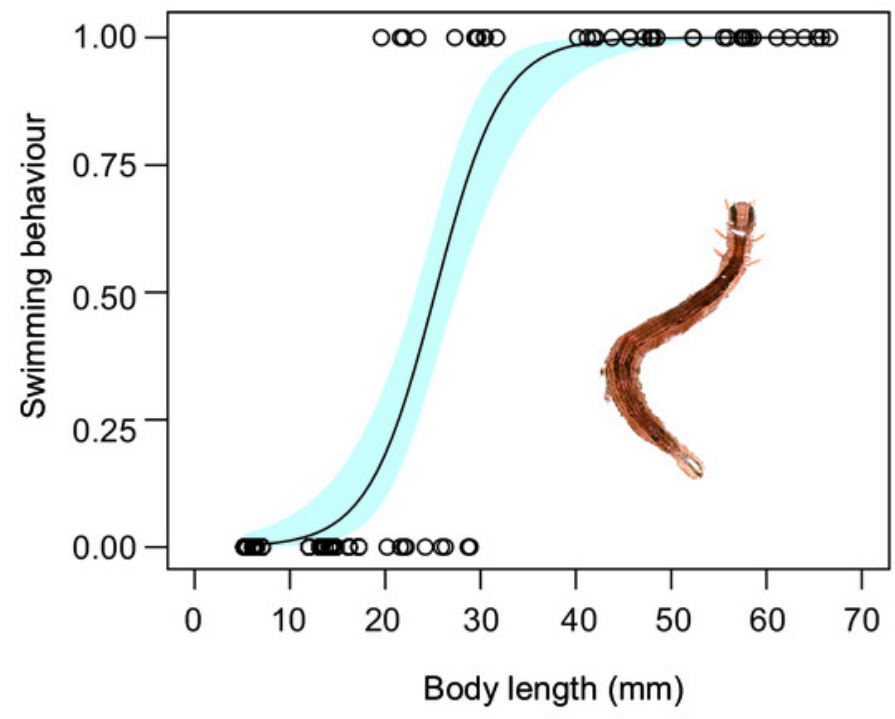

(b)

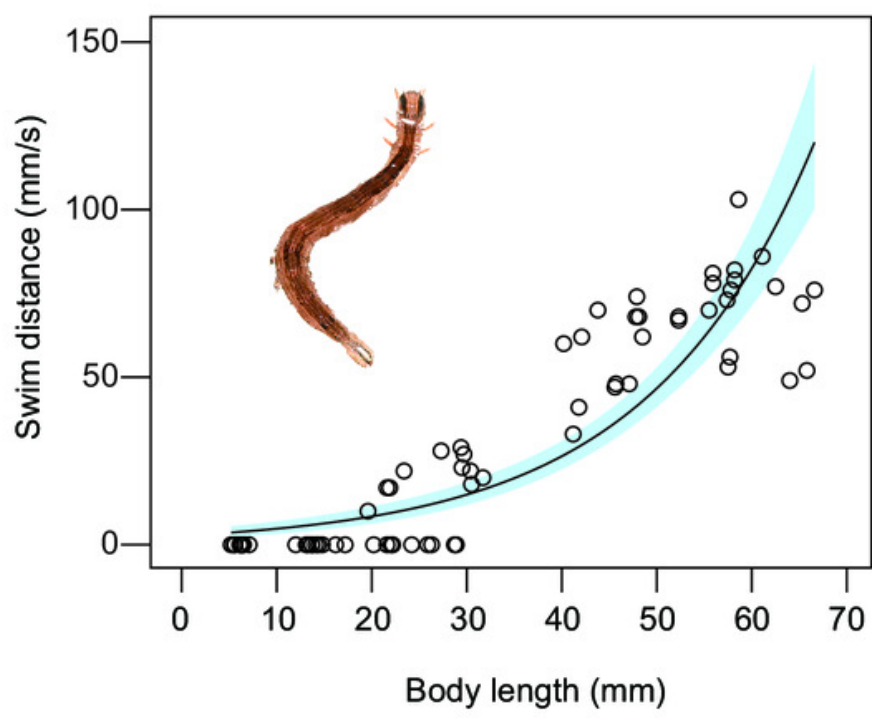

Figure 3 
Figure 4

Figure 4 Larval morphology of Hypopyra vespertilio.

(a) A larva on a host plant leaf. (b) A larva on the water surface. Hypopyra vespertilio larvae have three pairs of thoracic legs (T1-T3) and five pairs of abdominal prolegs (A3-A6 and A10). Photo credit: S. Sugiura.

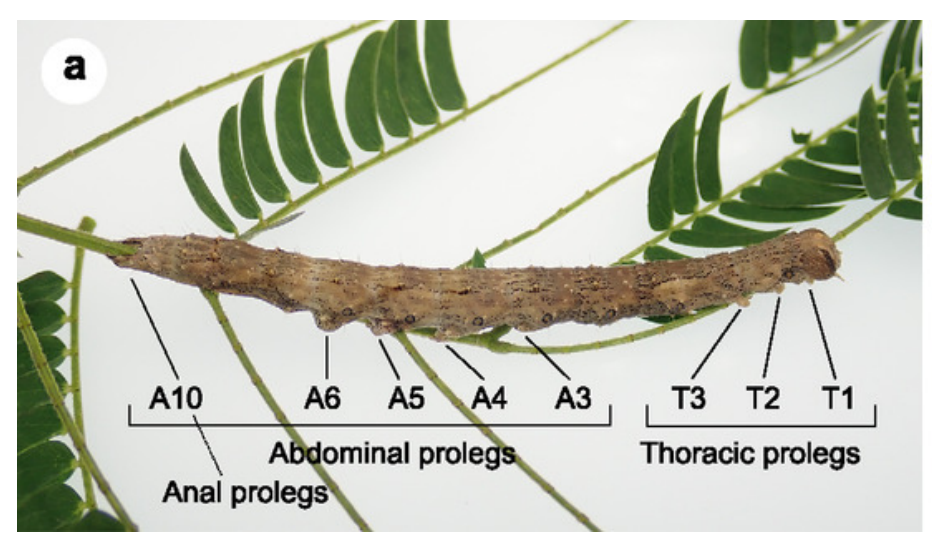

b

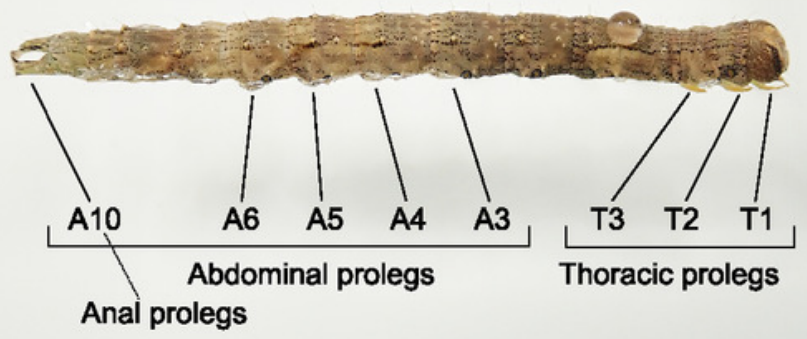

